\title{
Metamaterial Integrated Folded Dipole Antenna with Low SAR for 4G, 5G and NB-IoT Applications
}

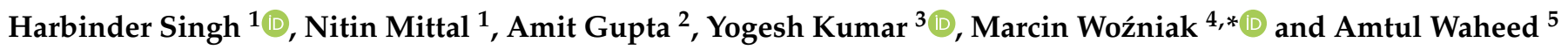 \\ 1 Department of Electronics and Communication Engineering, Chandigarh University, \\ Mohali 140413, Punjab, India; harbinder.ece@cumail.in (H.S.); nitinmittal.me@cumail.in (N.M.) \\ 2 Department of Electronics and Communication Engineering, I.K Gujral Punjab Technical University, \\ Jalandhar 144603, India; dr.amitgupta@ptu.ac.in \\ 3 Indus Institute of Technology \& Engineering, Indus University, Rancharda, Via Thaltej, \\ Ahmedabad 382115, India; yogeshkumar.ce@indusuni.ac.in \\ 4 Faculty of Applied Mathematics, Silesian University of Technology, 44-100 Gliwice, Poland \\ 5 Department of Computer Science, College of Arts and Science, Prince Sattam Bin Abdul Aziz University, \\ Wadi Ad-Dwasir 11991, Saudi Arabia; w.amtul@psau.edu.sa \\ * Correspondence: marcin.wozniak@polsl.pl
}

Citation: Singh, H.; Mittal, N.; Gupta, A.; Kumar, Y.; Woźniak, M.; Waheed, A. Metamaterial Integrated Folded Dipole Antenna with Low SAR for 4G, 5G and NB-IoT Applications. Electronics 2021, 10, 2612. https://doi.org/10.3390/ electronics10212612

Academic Editor: Reza K. Amineh

Received: 2 September 2021

Accepted: 22 October 2021

Published: 26 October 2021

Publisher's Note: MDPI stays neutral with regard to jurisdictional claims in published maps and institutional affiliations.

Copyright: (c) 2021 by the authors. Licensee MDPI, Basel, Switzerland. This article is an open access article distributed under the terms and conditions of the Creative Commons Attribution (CC BY) license (https:// creativecommons.org/licenses/by/ $4.0 /)$.

\begin{abstract}
The fast growth of wireless technology for mobile communication devices requires broad bandwidth, high data rate facilities and compact device size. The solution to the next generation user equipment is high data rate $4 \mathrm{G} / 5 \mathrm{G}$ technologies. In this research, wideband antenna design was analyzed and evaluated for 4G, 5G and NB-IoT applications. CST microwave studio was used for simulations and investigations of the performance parameters. The antenna was designed as a folded dipole with a tunable bandwidth and resonates for 5G NR n78, NR-IoT bands B1, B2, and B25, and eleven TDD LTE frequency bands with a bandwidth percentage and minimum scattering loss of $69.02 \%$ and $-42 \mathrm{~dB}$ respectively. Additionally, the designed antenna is small $\left(35 \times 48 \times 1.62 \mathrm{~mm}^{3}\right)$ and planar in structure and can be easily integrated with radio equipment. The antenna design was also investigated for SAR minimization and gain enhancement using metamaterial integration. For all operating frequency bands, the antenna design results in a considerable gain improvement. The metamaterial was shown to be an excellent absorber of radiation, particularly in high frequency regions. This research also included a SAR examination with and without metamaterial integration. SAR values were found to be significantly reduced throughout all operating bands. The results were validated by fabricating the design prototype on FR-4 substrate for 4G, 5G and IoT bands. The antenna will be possibly used for communication in high data rate applications.
\end{abstract}

Keywords: 4G; 5G; FDD; IoT; LTE; NR; TDD

\section{Introduction}

The continuous escalation in the number of wireless users is estimated to be expanded ten-fold by the end of 2025. There will be a need for more efficient technology, enhanced data rates and better spectrum utilization techniques. The 5G (Fifth Generation) is the latest generation to roll out the extremely high data rate services, such as enhanced mobile broadband (eMBB), massive machine type communications (mMTC), ultra-reliable, and low-latency communications (URLLC), in addition to vehicle to everything (V2X) communications in the near future [1]. The 5G networks will significantly improve the performance over the current 4G (Fourth Generation) systems and will also offer seamless connectivity to numerous devices by integrating different technologies, intelligence and flexibility. By comparison, $4 \mathrm{G}$ technology provides high quality video and audio services only. The Long Term Evolution (LTE) standard for 4G uses DSP (Digital System Processor) in addition to the modulation techniques to increase the data rates, and is incompatible with the 2G (Second Generation) and 3G (Third Generation) network. Thus, a separate 
radio spectrum is required. Leading mobile operators, global vendors and developers are launching NB-IoT (Narrow Band-Internet of Things) and LTE-M (LTE for machines) networks as an integral part of their long-term 5G IoT strategies. The NB-IoT is an LPWA (Low Power Wide Area) standard operating in the licensed frequency bands. It is better in terms of latency, quality and reliability in comparison to Sig-Fox and LoRa, which works on license free bands [2].

Existing cellular networks are evolving to deliver service to billions of new devices providing complete IoT connectivity in the $5 \mathrm{G}$ era. The increasing data demand requires an emergent number of frequency bands to be used in $4 \mathrm{G}$ and $5 \mathrm{G}$ applications. The LTE standard supports frequency division duplexing (FDD) and time division duplexing (TDD). The paired FDD LTE band can simultaneously transmit on two frequencies-one for uplink and the other for downlink. Alternatively, TDD LTE bands are unpaired because they share the same frequency for uplink and downlink with the help of the time-multiplexing technique. Thus, a different frequency spectrum allocation is required for TDD and FDD LTE bands. Numbers are being allocated to differentiate the LTE bands. The FDD LTE bands are being allocated with numbers 1 to 32 , whereas 33 to 43 are allocated to TDD LTE bands [3]. These bands are regularly updated for necessary additions in the regulatory meetings of ITU (International Telecommunication Union). Although some of the bands are overlapping, the distribution is feasible, because the possibility of transmission for TDD and FDD at the same time, and for the same LTE frequency band, is less likely to happen [4]. Currently, the LTE TDD unpaired frequency bands are preferred for mobile communications.

3GPP (Third Generation Partnership Project) released the 5G NR (New Radio) bands. Two radio spectra have been defined for these- one for sub- $6 \mathrm{GHz}$ and the other for the millimeter wave band [5]. The low frequency sub-6 GHz band has low path loss and better coverage in contrast to high frequency millimeter wave bands [6]. Additionally, the sub- $6 \mathrm{GHz}$ band is being widely used in the current 4G LTE operations and will probably play a crucial role in the pre- $5 \mathrm{G}$ operations. The $5 \mathrm{G}$ NR spectrum defined the frequency of 3.3 to $3.8 \mathrm{GHz}$ as the $\mathrm{n} 78$ band.

In 3GPP Release 13, the NB-IoT specification was finalized and allocated with fourteen frequency bands. Four more (B11, B25, B31 and B70) bands were allocated to the service in release 14. Release 15 specified seven additional bands (B4, B14, B71, B72, B73, B74 and B85) [7].

These different bands' operations can be obtained by using a multiple-input multipleoutput (MIMO) antenna system or frequency reconfiguration operations. In recent years, a number of MIMO and frequency reconfigurable antennas have been explored for different band coverages. MIMO antennas for band nos. 39 and 44 were designed by [8] respectively. In addition, [9] designed a band no. 44 antenna using ferrite as a substrate with permeability and permittivity of 3.7 and 7.8, respectively, with an optimized dimension of $55 \times 110 \times 7 \mathrm{~mm}^{3}$. In comparison to [9], a ceramic-based antenna was proposed by [10] and resulted in a diminution of volume by $22 \%$ compared to the one not using the ceramic substrate, covering LTE band nos. 39, 40 and 44 with low correlation coefficients, to be used as MIMO antennas. The well-known IFA (Inverted F Antenna) [11] was modified for LTE band nos. 41 and 44 on a realistic PCB with dimensions of $100 \times 40 \mathrm{~mm}^{2}$ for MIMO operations. In comparison to this [11], a MIMO antenna for the LTE band no. 7/17/13/20 was presented by [12], which requires a T-shaped dc line with two pin diodes for a reconfigurable frequency with the overall dimensions of $5 \times 125 \times 1 \mathrm{~mm}^{3}$ to be used for laptop applications. A reconfigurable triple band tablet computer antenna for the LTE operation was proposed using the IFA/loop antenna [13] to cover the TDD LTE low, middle and high bands with an overall dimension of $160 \times 200 \times 3 \mathrm{~mm}^{3}$. The research work of [13] was further improved for miniaturization in [14] with a wide band operation to cover the same TDD LTE low, middle and high bands that were previously used [13], but without the use of MIMO or frequency reconfigurable operations. The overall dimensions of [14] were reduced to $75 \times 140 \times 5.8 \mathrm{~mm}^{3}$. The dimensions of the antenna can be reduced to 
$38.5 \times 25 \mathrm{~mm}^{2}$ with the use of an asymmetric ground plane [15] with the band coverage of 40, 42 and 43. LTE base station antenna with MIMO operations was introduced by [16] to switch between LTE bands of 2.39-2.52 GHz and 1.825-2.925 GHz. The MIMO requirements can be avoided with the use of parasitic components [17] that can cover LTE low and high band applications with overall dimensions of $140 \times 70 \times 5 \mathrm{~mm}^{3}$.

Although the majority of designs available in the literature are compact, they focus only on some of the frequency bands, and those supporting a large number of bands are complex in design. Currently, most of the telecom operators are working in the $4 \mathrm{G}$ LTE service on the $2300 \mathrm{MHz}$ TDD LTE band, i.e., band no. 40, and are in the process of including more bands for their growing data services. Thus, there will be high demand for small-size antennas in the near future that can support 4G, 5G and IoT bands to solve the problem of band congestion. Metamaterial integrated antennas can be an excellent solution for meeting such demands. Double Negative (DNG) metamaterials are unnatural materials that may mimic the negative behavior of permittivity and permeability. This negative behavior leads to a negative refractive index, which may exhibit many unnatural properties, such as backward wave propagation, negative refraction, inversion of the Doppler effect and Snell's law [18]. These extraordinary properties may be useful in controlling the wave radiation behavior of electromagnetic waves [19]. The integration of metamaterial with a patch antenna can be used to address many of the limitations $[20,21]$.

The designed antenna presented in this research work focuses on achieving a wide bandwidth to cover $4 \mathrm{G} / 5 \mathrm{G} / \mathrm{IoT}$ bands with a compact size to meet the requirements of radio equipment. The proposed antenna design is simple and planar in structure, and can be used in any radio device for LTE, NR and NB-IoT operations. Moreover, the design supports LTE bands from 33 to 43, NR-IoT bands B1, B2 and B25, and the 5G NR n78 band on a single chip for $4 \mathrm{G} / 5 \mathrm{G} / \mathrm{IoT}$ applications with a compact size of $35 \times 48 \times 1.62 \mathrm{~mm}^{3}$.

The remainder of the paper is structured in four sections. The metamaterial design and its specifications are addressed in Section 2. Section 3 discusses the detailed designing methodology for wideband achievement and results analysis. Section 4 presents detailed analysis of the metamaterial integrated antenna and related health hazards. Section 5 summarizes the findings and presents conclusions.

\section{DNG Metamaterial Design}

The latest development in wireless communication systems has resulted in high demand for compact-size antennas that can handle the hazardous impacts of radiation on the human body [22]. Metamaterial integrated antennas have the potential to be an effective option for addressing these requirements [23]. The metamaterial can be designed using CRLH (Composite Right Left Hand) theory by implementing the circuit elements' equivalences [24,25].

Circuit components can be realized by implementing the inductance and capacitance equivalence using the microstrip line technique. The metamaterial is designed using the modified complementary metallic cross (CMC) for the inductance and capacitance equivalent of CRLH metamaterial [26]. The metallic structure is printed on the face side of a $5 \times 5 \mathrm{~mm}^{2}$ FR4 substrate. The FR4 substrate has a thickness of $1.574 \mathrm{~mm}$ and a dielectric constant of 4.3. The conductivity and thickness of the metallic print on the FR4 substrate are considered in correlation to the actual data characteristic of annealed copper, and were chosen as $5.8 \times 10^{7} \mathrm{~S} / \mathrm{m}$ and $35 \mu \mathrm{m}$, respectively. The CMC behavior is analogous to that of inductance and capacitance equivalency. The structure's LC resonator behavior may be rationalized by considering the CMC length and gap width for inductance and capacitance equivalency, respectively (Figure 1). As the value of L2 increases, the capacitance equivalency diminishes, and more tweaking is available through the usage of W1. In contrast, raising L1 and W1 results in a rise in the sectional area, resulting in the escalation of inductance, although $\mathrm{W} 1$ has an influence on both procedures. The design was simulated using CST Microwave Studio to evaluate the refractive index, permittivity, and permeability using the approach described in [27]. 


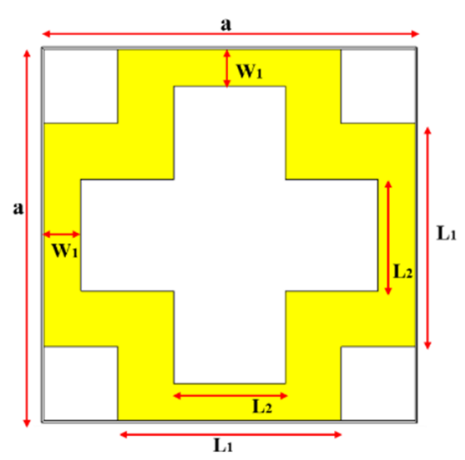

Figure 1. DNG metamaterial unit cell illustration.

The simulated results for central gap width (w1) of $0.5 \mathrm{~mm}$, and outer (L1) and inner (L2) width of 3 and $1.5 \mathrm{~mm}$, respectively, are illustrated in Figures 2-4. The permittivity, permeability and refractive index for the $\mathrm{CMC}$ is zero at $17.23 \mathrm{GHz}$. As a result, the material is capable of sustaining forward waves greater than $17.23 \mathrm{GHz}$ and backward waves less than 17.23 GHz. Additionally, the material transitions seamlessly from the Double Negative to the Double Positive spectrum. In general, a DNG metamaterial with negative index properties up to $17.23 \mathrm{GHz}$ was designed and can be used for negative index applications.

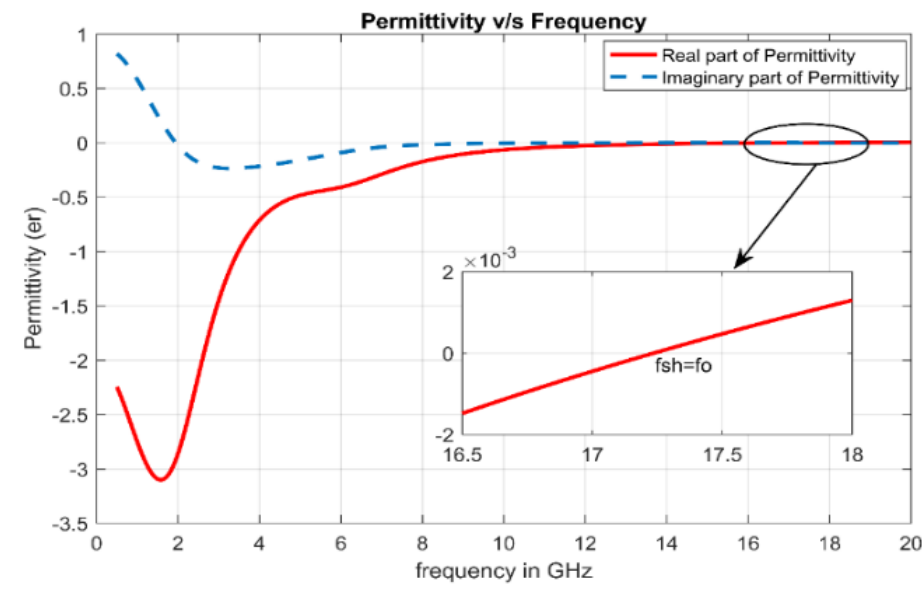

Figure 2. Retrieved permittivity for the structure.

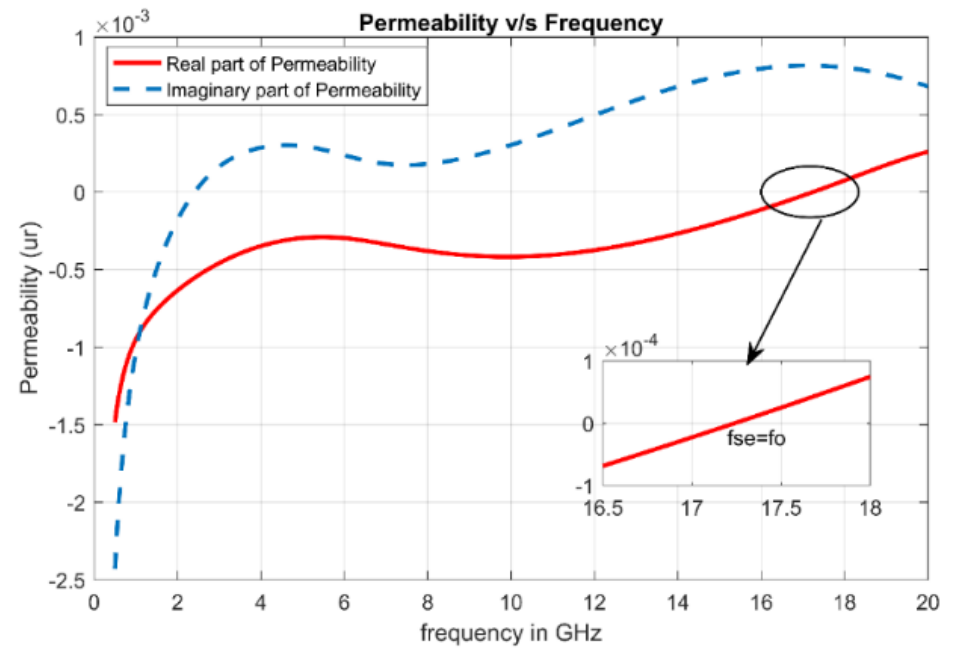

Figure 3. Retrieved permeability for the structure. 


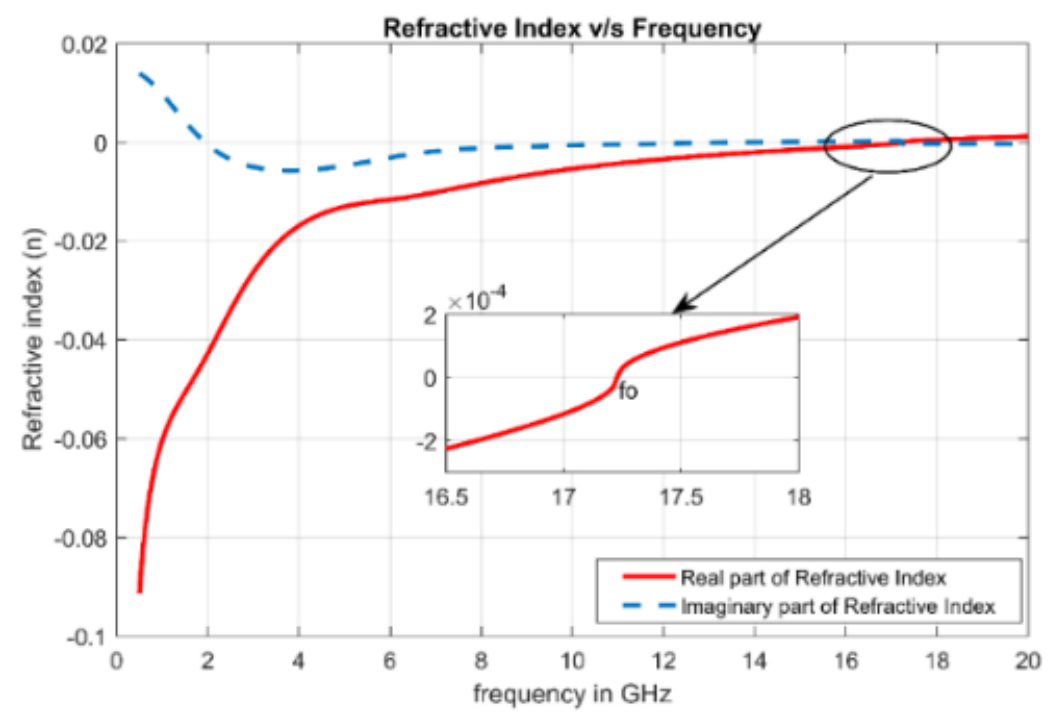

Figure 4. Retrieved refractive index for the structure.

\section{Antenna Design and Result Analysis}

The antenna was designed for wideband operations, to support the wide range of frequencies between $1.8 \mathrm{GHz}$ to $3.8 \mathrm{GHz}$. The antenna was designed as a patch antenna with a dipole like a patch element on FR4 (lossy) substrate, as shown in Figure 5. The dielectric constant $\left(\in_{r}\right)$ of the substrate was chosen to be 4.3 with a loss tangent and thickness of 0.02 and $1.574 \mathrm{~mm}$, respectively. The initial dimensions were estimated with the use of the dipole antenna theory. The input impedance of the half wave dipole [28] with infinitesimally thin width can be defined in terms of the length of the dipole antenna $\left(L_{d}\right)$ and phase constant $(\beta)$ as:

$$
R_{\text {in }}=24.7\left(\frac{\beta L_{d}}{2}\right)^{2.5}
$$

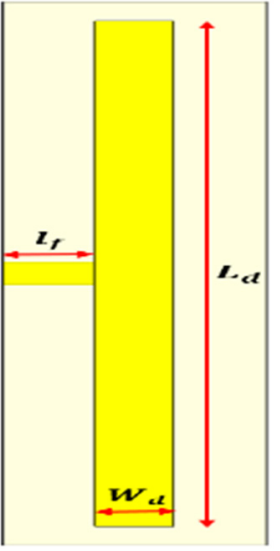

Figure 5. Illustration of dipole inspired patch antenna.

The dipole length expression can be simplified further by considering the input impedance to be $50 \Omega$, considering the impedance matching requirement of the antenna with a feeding port.

$$
L_{d}=0.422 \lambda
$$

The bandwidth for the thin dipole antenna is much narrower in comparison to the thick dipole antenna. The length of the thick cylindrical dipole with radius ' $a$ ' can be corrected as:

$$
L_{d}=0.422 \lambda F
$$


where $F$ is the correction factor and is given as:

$$
F=\frac{L_{d} / a}{1+L_{d} / a}=\frac{L_{d}}{L_{d}+a}
$$

For an infinitesimally thin dipole antenna $\mathrm{r}$ is negligible and $F$ is unity, but for a thick dipole antenna, $F$ is smaller than unity. Therefore, the corrected dipole antenna length can be estimated using Equations (3) and (4) as:

$$
L_{d}=0.422 \lambda-a
$$

To obtain precise results the feed length $\left(l_{f}\right)$ needs to be included as:

$$
L_{d}+l_{f}+a=0.422 \lambda
$$

The equivalent radius theory is applied to approximate the equivalent width $\left(W_{d}\right)$ of the rectangular patch. The equivalent radius represents the radius of a circular wire whose capacitance is equal to that of the noncircular geometry, considering the length to be equivalent. The equivalent radius for the rectangular dipole is approximated as:

$$
W_{d}=4 a
$$

The wideband antenna designed in this research is not a wire antenna but a patch antenna with a dielectric layer, which needs to be considered for calculating the effective size and can be modified as:

$$
\begin{gathered}
k\left(L_{d}+l_{f}+a\right)=0.422 \lambda \\
L_{d}=\left(\frac{0.422 \lambda}{k}\right)-\frac{W_{d}}{4}-l_{f}
\end{gathered}
$$

The constant $\mathrm{k}$ is estimated as 1.15 according to the procedure outlined in [29]. Thus, it is clear from the mathematical expression that the larger the length, the smaller the resonating frequency, and vice versa. The same behavior was examined in the full wave electromagnetic simulations and is represented in Figure 6. The resonating frequency observed is inversely proportional to the length of the dipole.

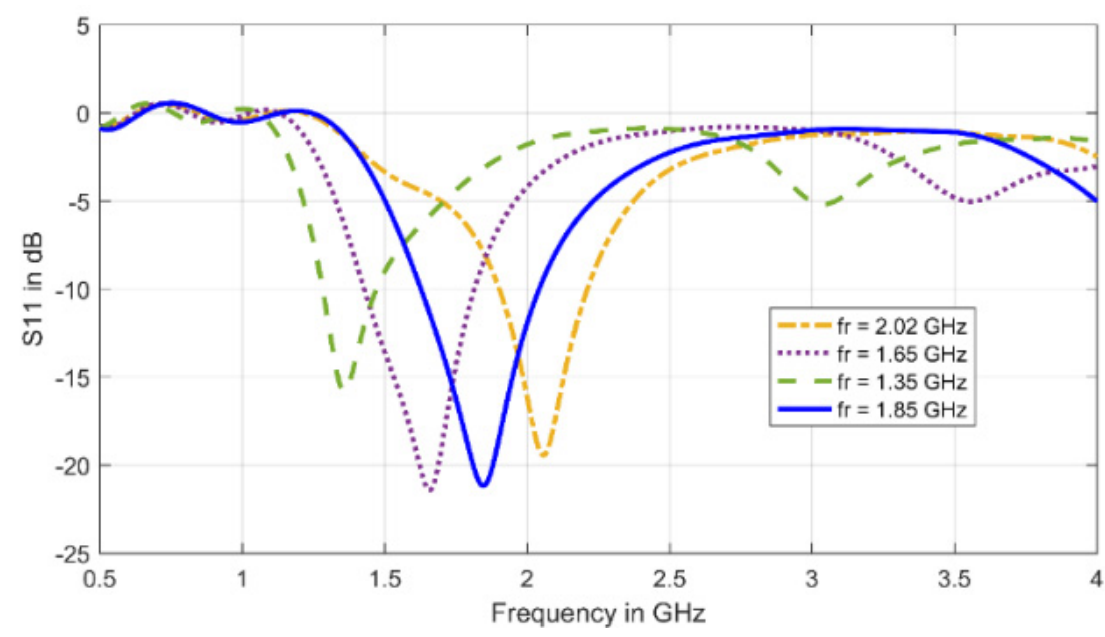

Figure 6. Scattering plot for different dipole lengths.

The size of the initial design is estimated using Equation (9) for the lowest resonating frequency of $1.85 \mathrm{GHz}$. The length of feed and width of the rectangular dipole was chosen to be 5.7 and $4 \mathrm{~mm}$, respectively, and the scattering plot obtained for this is illustrated in 
Figure 6. Better bandwidth can be achieved by escalating the radius of the dipole, which is equivalent to dipole width escalation.

A multiple width dipole antenna is shown in Figure 7, which is capable of achieving the different resonance frequencies in accordance with the length and width combinations of multiple elements. The width and length of the dipole elements are considered as controlling elements to control the overall bandwidth and resonance of the antenna. The wideband achieved can be understood by arranging the desired resonating frequencies in ascending order. They can be assumed to be further divided into four close bands. The first of these can be designated as low frequency LTE bands and consists of band nos. 35, 39, 33, 37 and 36 . The two middle frequencies LTE bands can be identified as band nos. 34 and $40,41,38$ respectively. The last high frequency bands consist of LTE band nos. 42,43 and NR n78. The NB-IoT bands almost coincide with the LTE bands, so they are not assumed separately for wideband accomplishment. These close bands can be obtained by dipole elements 1 and 3 for low frequency LTE bands and elements 5 and 2 for middle frequency LTE bands. Similarly, high frequency bands can be achieved through dipole element 4 . The simulations were performed using CST microwave studio with the length and width of the feeding strip of 5.6 and $4.7 \mathrm{~mm}$, respectively. The ground layer is considered to be infinite with some extra spacing for the substrate in addition to the maximum width and length of the dipole to compensate for the fringing fields. A few of the selected cases for different controlling elements are represented in Figure 8 and Table 1.

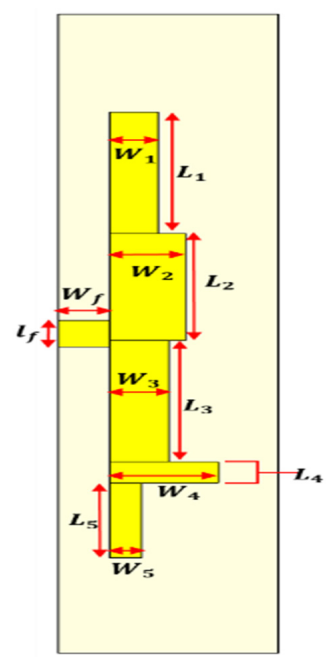

Figure 7. Illustration of variable width dipole antenna.

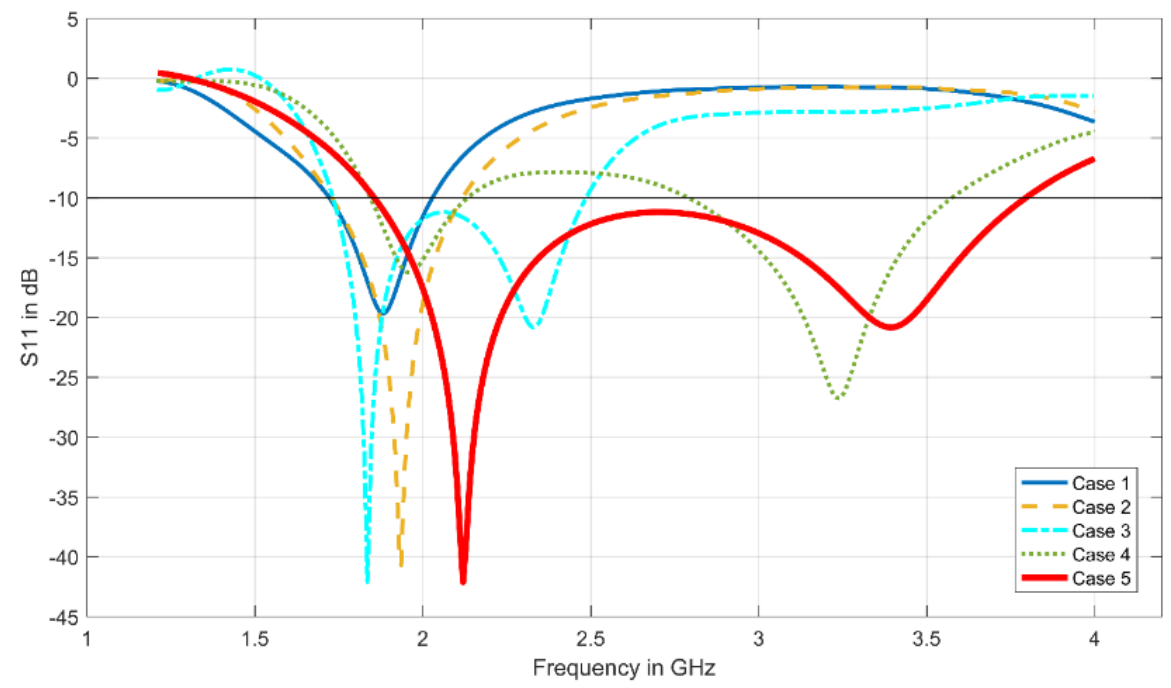

Figure 8. S parameter for different antenna configurations. 
Table 1. Controlling elements of variable width dipole.

\begin{tabular}{|c|c|c|c|c|c|c|}
\hline \multirow{2}{*}{\multicolumn{2}{|c|}{ Controlling Elements in mm }} & \multicolumn{5}{|c|}{ Case } \\
\hline & & 1 & 2 & 3 & 4 & 5 \\
\hline \multirow{2}{*}{ High frequency elements } & $\mathrm{L}_{4}$ & 10 & 8 & 7 & 4.5 & 7.5 \\
\hline & $\mathrm{W}_{4}$ & 1 & 5 & 6 & 9 & 10 \\
\hline \multirow{4}{*}{ Middle frequency elements } & $\mathrm{L}_{5}$ & 25 & 20 & 18 & 17 & 16 \\
\hline & $W_{5}$ & 1 & 2 & 2.5 & 2.5 & 3 \\
\hline & $\mathrm{L}_{2}$ & 20 & 21 & 22 & 23 & 23 \\
\hline & $W_{2}$ & 1 & 3 & 5 & 6 & 7 \\
\hline \multirow{4}{*}{ Low frequency elements } & $\mathrm{L}_{1}$ & 31 & 29 & 27 & 27 & 26 \\
\hline & $W_{1}$ & 1 & 2 & 3.5 & 4 & 4.5 \\
\hline & $\mathrm{L}_{3}$ & 30 & 30 & 27 & 27 & 26 \\
\hline & $W_{3}$ & 1 & 3 & 4 & 5 & 5.5 \\
\hline $\begin{array}{c}\mathrm{BW} \\
f_{L}-f_{H} \\
(\mathrm{GHz})\end{array}$ & & 1.7 to 2.05 & 1.7 to 2.12 & 1.7 to 2.5 & $\begin{array}{l}1.85 \text { to } 2.12 \text { and } \\
2.75 \text { to } 3.6\end{array}$ & 1.85 to 3.8 \\
\hline
\end{tabular}

The initial tuning operations are obtained using the common width dipole elements such that the variable width dipole antenna acts as a single thin dipole antenna. The common width dipole resonates at a frequency of $1.8 \mathrm{GHz}$ and is in good agreement with the second resonance frequency, as per the theoretical calculations of Equation (9). The scatter plot obtained for the same is illustrated in Figure 8 as case 1 . The resonance and bandwidth can be controlled further according to the equivalent length and width combination of the five element dipoles. The $350 \mathrm{MHz}$ bandwidth obtained in case 1 is escalated in case 2 by increasing the elements widths and slightly decreasing the length to incorporate the high frequencies. However, the $420 \mathrm{MHz}$ bandwidth obtained in case 2 is not sufficient to include the middle and high bands. Thus, the length and width of the dipole elements are further optimized to include the higher frequency bands. Case 3 resonates for two frequencies; the lower resonating frequency of $1.8 \mathrm{GHz}$ is due to the total equivalent length and the higher resonating frequency of $2.3 \mathrm{GHz}$ is supported by the sub-combinations of dipole element lengths. The total bandwidth achieved in case 3 is $800 \mathrm{MHz}$, in comparison to $420 \mathrm{MHz}$ obtained in case 2. However, all three cases are not able to cover the high frequency bands. It should be noted that there is a small gap between the middle and high frequency bands. The same process was attempted to be incorporated in case 4 , by emphasizing dipole element 4 , which nearly covers low frequency and high frequency bands with bandwidths of 270 and $850 \mathrm{MHz}$, respectively. The essential operational bandwidth can be achieved in the same escalating manner but will result in a bulky antenna. The basic compact size requirement of the radio device is obtained by folding the elements of the dipole in the minimum possible substrate space with a cross-section area of $35 \times 48 \mathrm{~mm}^{2}$, as illustrated in Figure 9 . However, the size minimization may result in bandwidth depletion because of the finite, rather than infinite, ground, and this can be addressed by a defective ground structure with an optimized length of $4 \mathrm{~mm}$, as shown in Figure 10. The length and width of the feeding element are optimized to 5.6 and $10 \mathrm{~mm}$, respectively.

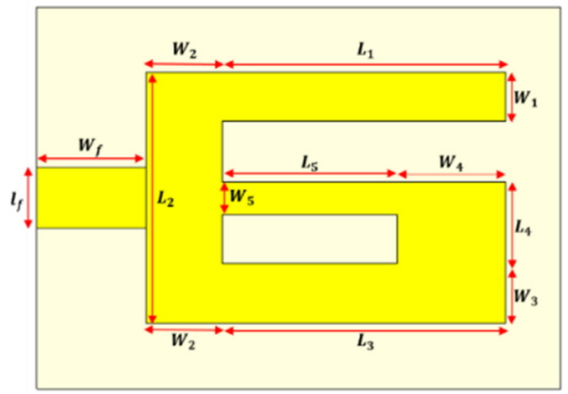

Figure 9. Front view of antenna design. 


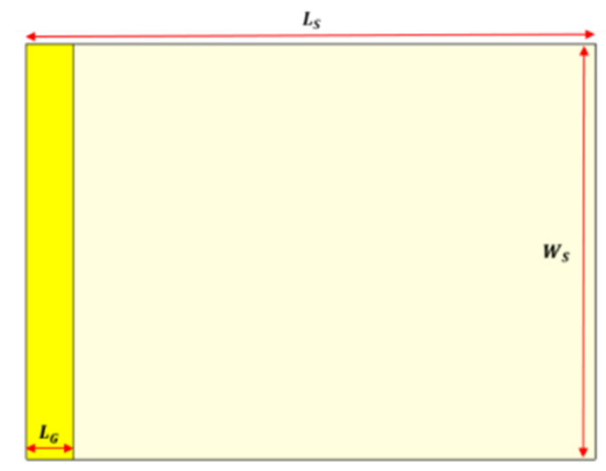

Figure 10. Back view of antenna design.

A notch at $2.7 \mathrm{GHz}$ is observed in the operational bandwidth by feeding element 5 from both ends via element 2 apart from the conventional connection with element 4 . The dimensions and the scattering plot for the folded dipole antenna are represented as case 5. The folded dipole resonates from 1.85 to $3.8 \mathrm{GHz}$ with a bandwidth of $1.95 \mathrm{GHz}$ and 69.02 of bandwidth percentage with two peaks of resonance. The folded design is capable of covering the 5G NR n78, NR-IoT bands B1, B2 and B25, and eleven TDD LTE bands from 33 to 43 . The minimum scattering loss observed for the design is $-42 \mathrm{~dB}$ with $50.22 \Omega$ of impedance; therefore, the antenna can be fed directly with a $50 \Omega$ line without the need for a separate cascaded impedance matching circuit.

Figures 11 and 12 represent the radiation pattern for all the covered bands in XY and YZ planes. A figure-of-eight pattern is observed in the azimuth plane for low and middle frequencies, whereas the pattern approximates the figure-of-eight shape in high frequencies with less emission below the y axis. Thus, the ground plane contributes to radiation in the low and middle frequency bands and acts as a reflector for high frequency bands. By comparison, omnidirectional radiations are observed in the polar plane. The ground is observed to be a reflector at low wavelength and a radiator at high wavelength, which results in less radiation at 90 polar for increasing frequencies. Therefore, the antenna approximately radiates in a doughnut pattern.

Farfield Gain Abs (Theta $=90$ )
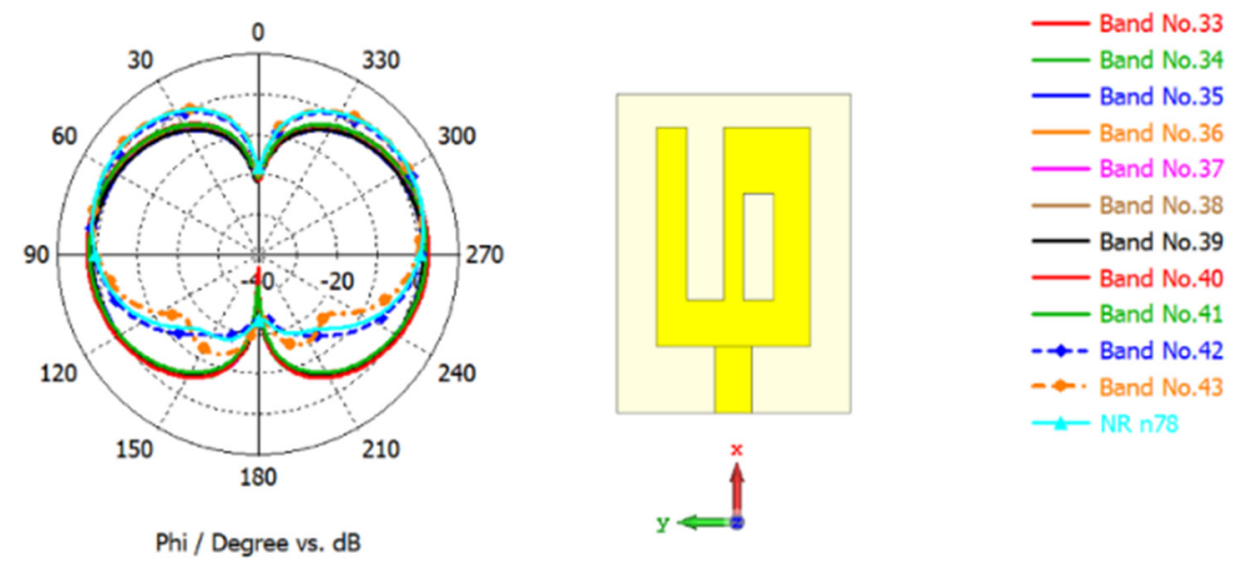

Figure 11. Antenna radiation pattern in the azimuth plane. 


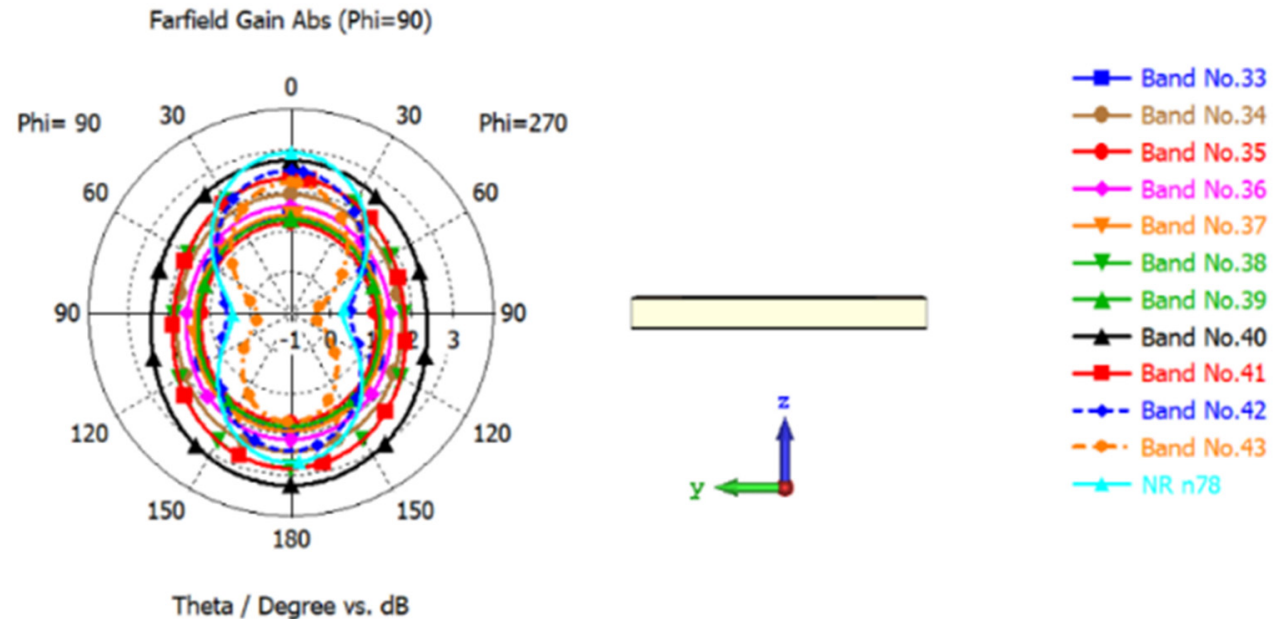

Figure 12. Antenna radiation pattern in the polar plane.

The gain values for the folded dipole antenna for different bands are detailed in Table 2. The gain observed for the low frequency LTE band is between 2.735 and $2.989 \mathrm{~dB}$ and that for middle frequency LTE bands is between 3.150 and $3.677 \mathrm{~dB}$. For high frequency LTE and NR bands, the gain is between 4.757 and $4.926 \mathrm{~dB}$. It is evident from all the obtained results that the designed antenna can resonate for $4 \mathrm{G} / 5 \mathrm{G} / \mathrm{IoT}$ bands with sufficient performance parameters.

Table 2. Gain for the folded dipole antenna.

\begin{tabular}{|c|c|c|c|}
\hline Band No. & $\begin{array}{c}\text { Frequency } \\
\text { (GHz) }\end{array}$ & $\begin{array}{l}\text { Gain } \\
\text { (dB) }\end{array}$ & Band Name \\
\hline $\mathrm{B} 2 \mathrm{U}$ & $1.85-1.91$ & 2.4778 & \multirow{6}{*}{ IoT Bands } \\
\hline B2D & $1.93-1.99$ & 2.6094 & \\
\hline $\mathrm{B} 25 \mathrm{U}$ & $1.85-1.915$ & 2.4815 & \\
\hline B25D & $1.93-1.995$ & 2.6113 & \\
\hline $\mathrm{B} 1 \mathrm{U}$ & $1.92-1.98$ & 2.5965 & \\
\hline B1D & $2.11-2.17$ & 2.7686 & \\
\hline 35 & $1.85-1.91$ & 2.735 & \multirow{5}{*}{ Low frequency LTE bands } \\
\hline 39 & $1.88-1.92$ & 2.801 & \\
\hline 33 & $1.90-1.92$ & 2.833 & \\
\hline 37 & $1.91-1.93$ & 2.865 & \\
\hline 36 & $1.93-1.99$ & 2.989 & \\
\hline 34 & $2.01-2.02$ & 3.150 & \multirow{4}{*}{ Middle frequency LTE Bands } \\
\hline 40 & $2.30-2.40$ & 3.640 & \\
\hline 41 & $2.49-2.69$ & 3.676 & \\
\hline 38 & $2.57-2.62$ & 3.677 & \\
\hline 42 & $3.40-3.60$ & 4.757 & \multirow{2}{*}{ High frequency LTE bands } \\
\hline 43 & $3.60-3.80$ & 4.926 & \\
\hline n78 & $3.30-3.80$ & 4.843 & 5G NR \\
\hline
\end{tabular}

The prototype was fabricated and tested to validate the performance of the antenna, and the photograph of the fabricated prototype is shown in Figure 13. Experimental results of the designed antenna were measured using Anritsu Vector Network Analyzer (VNA), model no. MS46322A. The measured and simulated S11 parameters of the fabricated an- 
tenna are illustrated in Figure 14. A good approximation between simulated and measured results was obtained.

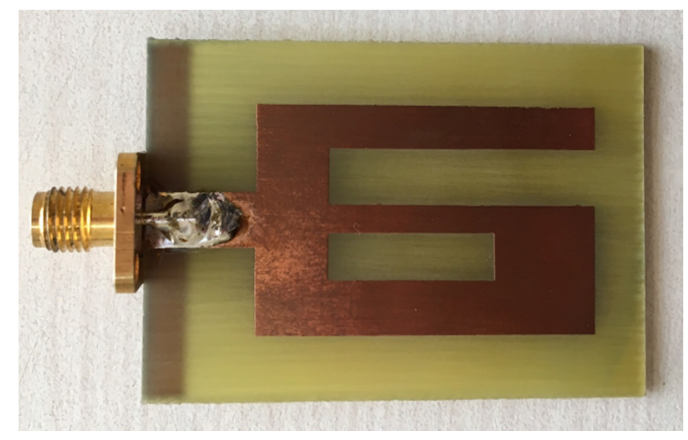

Figure 13. Photograph of the fabricated antenna.

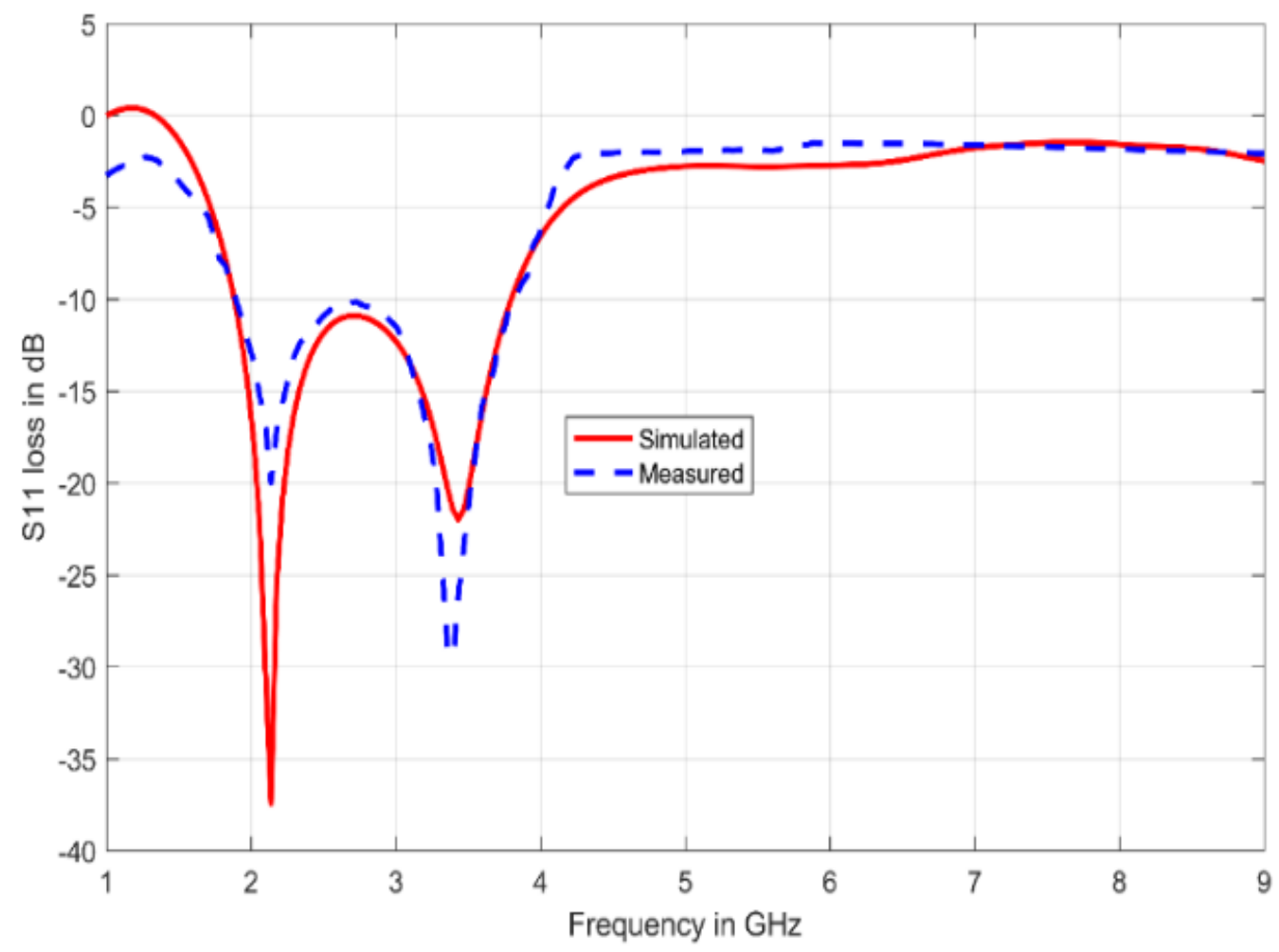

Figure 14. Measured and simulated S parameter.

Table 3 provides a comparison of the designed antenna with different reported designs in terms of size and bands. The designs presented in [8,9] resonate only on a single LTE band, and those of $[10,12,15,30]$ working on the multi-band but not on all of the bands. In comparison, the antenna designs reported in $[13,14,17]$ are capable of operating on most of the LTE bands. By comparison, those in [31-35] are capable of working in 5G NR sub-6 GHz bands in addition to some LTE bands, but are bulky and non-planar in structure. Many of the designs available in the literature considered the infinite ground or active switches for their operations. The folded dipole designed in this research is planar, compact and simple in structure, and resonates for 5G, 4G and IoT bands with sufficient radiation characteristics, bandwidth, gain and return loss. A 97\% size reduction was achieved by folding the dipoles in comparison to [31], 96\% in comparison to [32], 33\% in comparison to [33], 95\% in comparison to [34] and $96 \%$ in compassion to [35]. 
Table 3. Comparison of folded dipole design.

\begin{tabular}{|c|c|c|c|c|}
\hline Citation & Frequency Band & Maximum Gain (dB) & $\begin{array}{c}\text { Maximum } \\
\text { Efficiency (\%) }\end{array}$ & $\begin{array}{c}\text { Overall } \\
\text { Dimensions } \\
(\mathrm{mm})\end{array}$ \\
\hline [9] & 44 & 8.32 & - & $55 \times 110 \times 7$ \\
\hline [10] & $39,40,44$ & 7.1 & 70 & $110 \times 45 \times 6$ \\
\hline$[11]$ & 41,44 & - & 91 & $100 \times 40$ \\
\hline [12] & $7,13,17,20$ & - & 80 & $260 \times 200$ \\
\hline [13] & $33,34,35,36,37,38,39,40,41,42,43,44$ & 5.2 & 95 & $160 \times 200 \times 3$ \\
\hline [14] & $33,34,35,36,37,38,39,40,41,42,43,44$ & - & 92 & $75 \times 140 \times 5.8$ \\
\hline [15] & $40,42,43$ & 4.23 & 99 & $38.5 \times 25$ \\
\hline [17] & $33,34,35,36,37,38,39,40,41,44$ & - & 72 & $140 \times 70 \times 5$ \\
\hline [31] & $\mathrm{n} 78,38,40,41,42$ & 4 & - & $35.2 \times 49.5 \times 49.5$ \\
\hline [32] & n78, 42 & - & 70 & $75 \times 150 \times 6$ \\
\hline$[33]$ & $\mathrm{n} 78,42,43$ & 2.6 & - & $50 \times 50$ \\
\hline [34] & $\mathrm{n} 78,40,41,42$ & 6.8 & 69.5 & $5.7 \times 100 \times 100$ \\
\hline [35] & $\mathrm{n} 78,42,43$ & 8.95 & - & $75 \times 75 \times 13.1$ \\
\hline Folded dipole & $\begin{array}{c}33,34,35,36,37,38,39,40,41,42,43, \mathrm{~B} 1, \mathrm{~B} 2, \\
\mathrm{~B} 25, \mathrm{n} 78\end{array}$ & 4.044 & 92 & $35 \times 48 \times 1.62$ \\
\hline
\end{tabular}

\section{Metamaterial Integrated Antenna Design}

This section analyzes and evaluates the antenna performance with the designed CMC dual negative metamaterial. A metamaterial array of $6 \times 5$ unit cell elements was chosen for suitable coverage of the radiating element. The metamaterial is placed below the antenna and is separated by a small air gap(s) from the antenna plane, as illustrated in Figure 15. The scattering loss plot for different air gaps is illustrated in Figure 16.
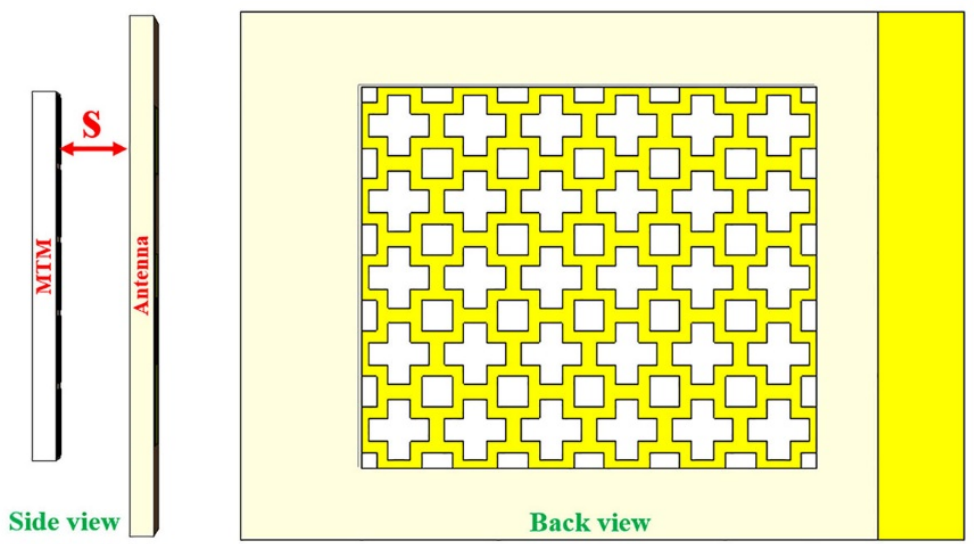

Figure 15. Metamaterial integrated antenna design.

It was observed that the metamaterial insertion exactly below the antenna plane disturbs the impedance matching. By comparison, the required bandwidth can be achieved with an accumulative air gap. After a separation of $2.5 \mathrm{~mm}$, the effect of the metamaterial on the required bandwidth is almost the same. In fact, a small increase in the bandwidth is observed at higher frequencies in comparison to the operation without the metamaterial. The main objective of the metamaterial insertion is to increase the gain and to control the radiation pattern for SAR (Specific Absorption Rate) minimization. The gain of the metamaterial integrated antenna for different air gaps is illustrated in Figure 17 The metamaterial integration with antenna design results in the gain enhancement in comparison 
to the design without the metamaterial. It can be observed from the gain plot that the greater air gap results in better gain because of the negative properties of the metamaterial, while resulting in a bulky antenna. Therefore, there is a tradeoff between size and gain. The optimum value of $10 \mathrm{~mm}$ was chosen for the air gap to maintain the compactness of the antenna design. The enhanced gain observed for LTE and NR bands at a $10 \mathrm{~mm}$ air gap is summarized in Table 4. Practically, the separation was achieved by using a foam substrate; the fabricated prototype and the measured S plot of the same are illustrated in Figures 18 and 19, respectively. A good agreement between measured and simulated results was achieved.

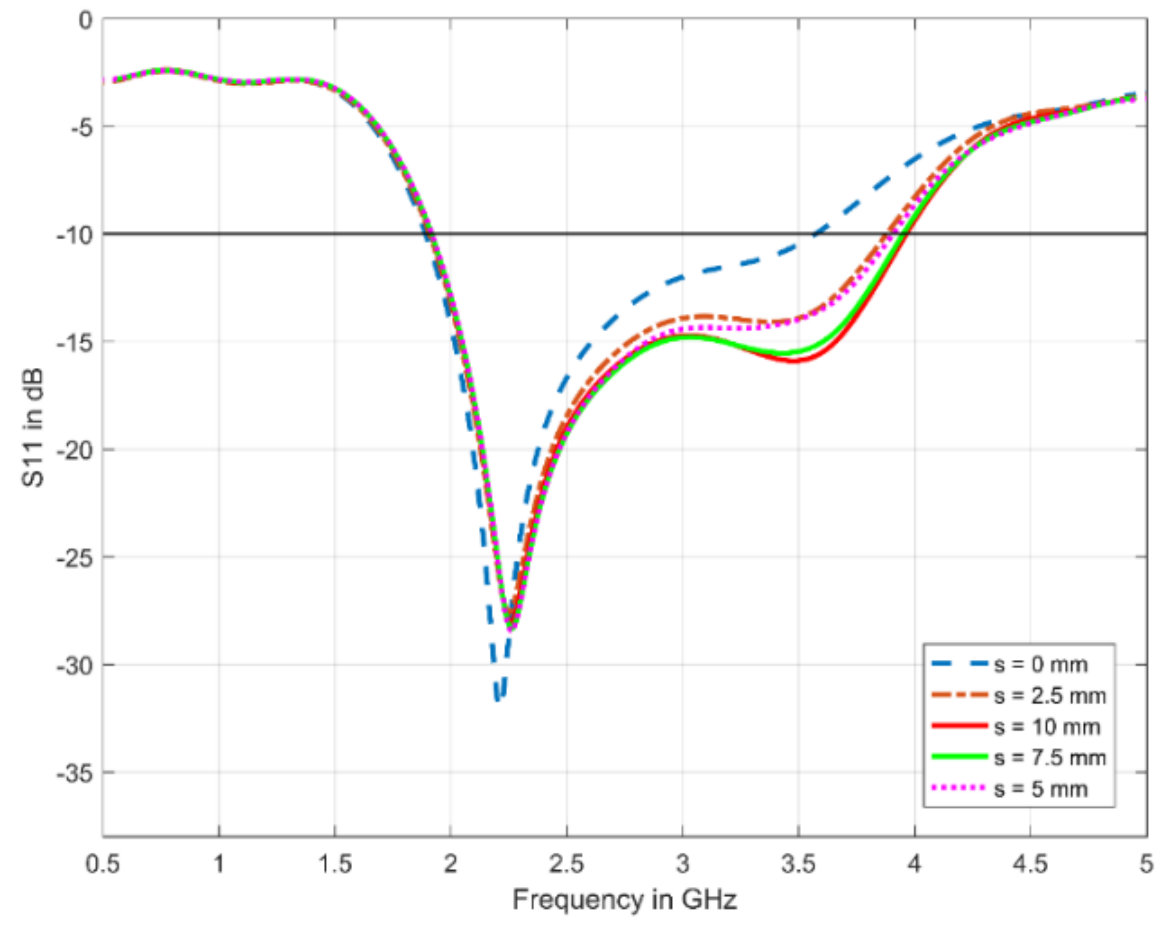

Figure 16. Scattering plot for different air gap.

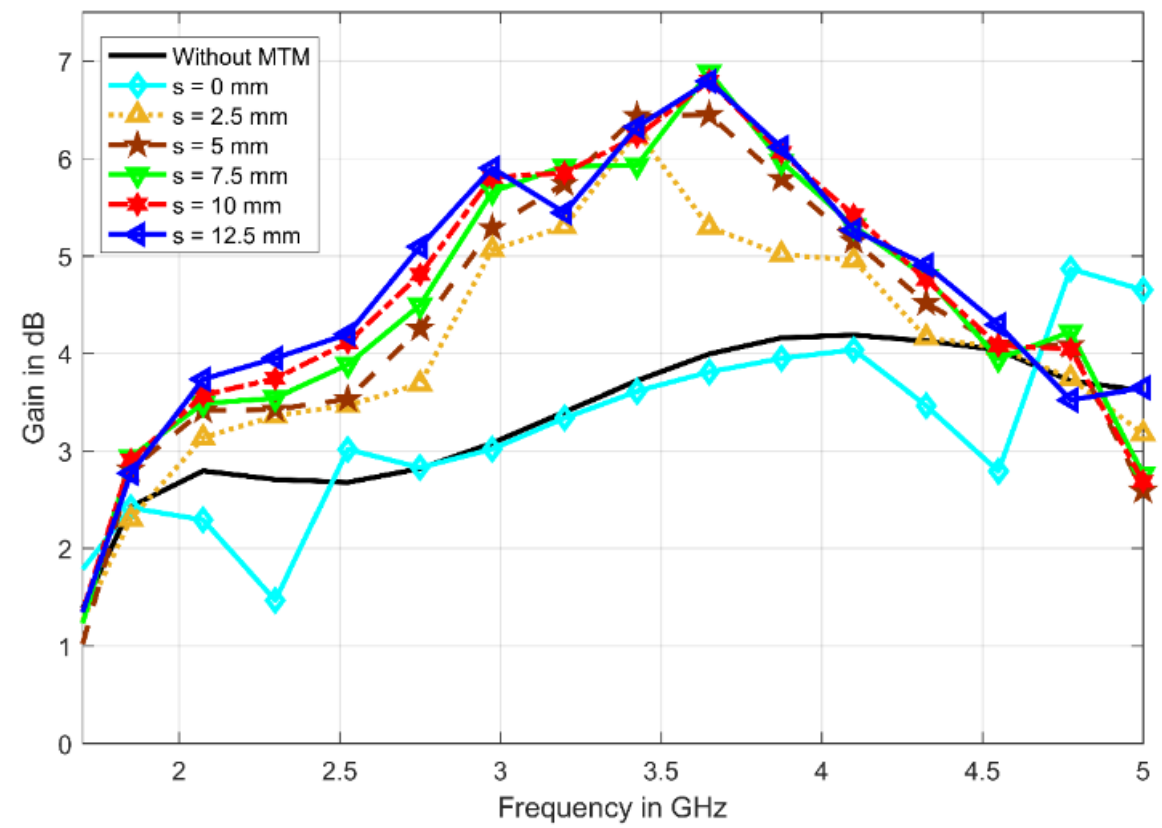

Figure 17. Gain plot for different air gaps. 
Table 4. Effect of metamaterial on antenna gain.

\begin{tabular}{|c|c|c|c|}
\hline Band No. & $\begin{array}{l}\text { Gain without Metamaterial } \\
\text { (dB) }\end{array}$ & $\begin{array}{l}\text { Gain with Metamaterial } \\
\text { (dB) }\end{array}$ & Band Name \\
\hline B2U & 2.477 & 2.998 & \multirow{6}{*}{ IoT Bands } \\
\hline B2D & 2.609 & 3.232 & \\
\hline B25U & 2.481 & 3.002 & \\
\hline B25D & 2.611 & 3.238 & \\
\hline $\mathrm{B} 1 \mathrm{U}$ & 2.596 & 3.202 & \\
\hline B1D & 2.768 & 3.619 & \\
\hline 35 & 2.583 & 3.084 & \multirow{5}{*}{ Low frequency LTE bands } \\
\hline 39 & 2.634 & 3.153 & \\
\hline 33 & 2.657 & 3.184 & \\
\hline 37 & 2.678 & 3.213 & \\
\hline 36 & 2.743 & 3.309 & \\
\hline 34 & 2.794 & 3.403 & \multirow{4}{*}{ Middle frequency LTE Bands } \\
\hline 40 & 2.656 & 3.788 & \\
\hline 41 & 2.716 & 4.340 & \\
\hline 38 & 2.718 & 4.346 & \\
\hline 42 & 3.825 & 6.701 & \multirow{2}{*}{ High frequency LTE bands } \\
\hline 43 & 3.893 & 6.668 & \\
\hline n78 & 4.044 & 6.824 & $5 \mathrm{G} \mathrm{NR}$ \\
\hline
\end{tabular}

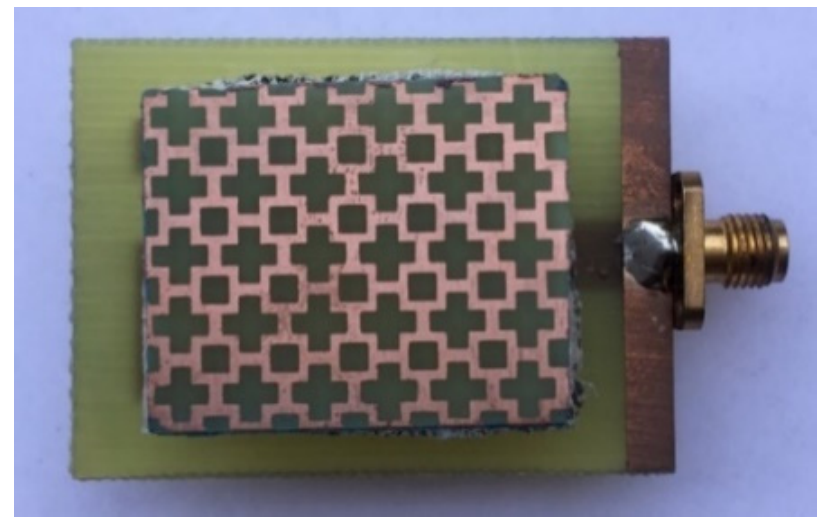

Figure 18. Fabricated prototype of the metamaterial integrated antenna.

The radiation patterns for the metamaterial integrated antenna in the azimuth and polar planes is represented in Figures 20 and 21 respectively. The DNG metamaterial acts as a good absorber for radiation, especially at high frequencies, because the metamaterial is placed below the antenna, which has almost no effect on the azimuth pattern. The pattern observed in the azimuth plane is approximately the same as that obtained in the operation without the metamaterial. An omnidirectional pattern is observed in the polar plane without the metamaterial. However, the metamaterial integrated antenna results in less emission in the lower half and greater emission in the upper half, especially at high frequency bands. Thus, the pattern was proven to be a good design for SAR reduction. 


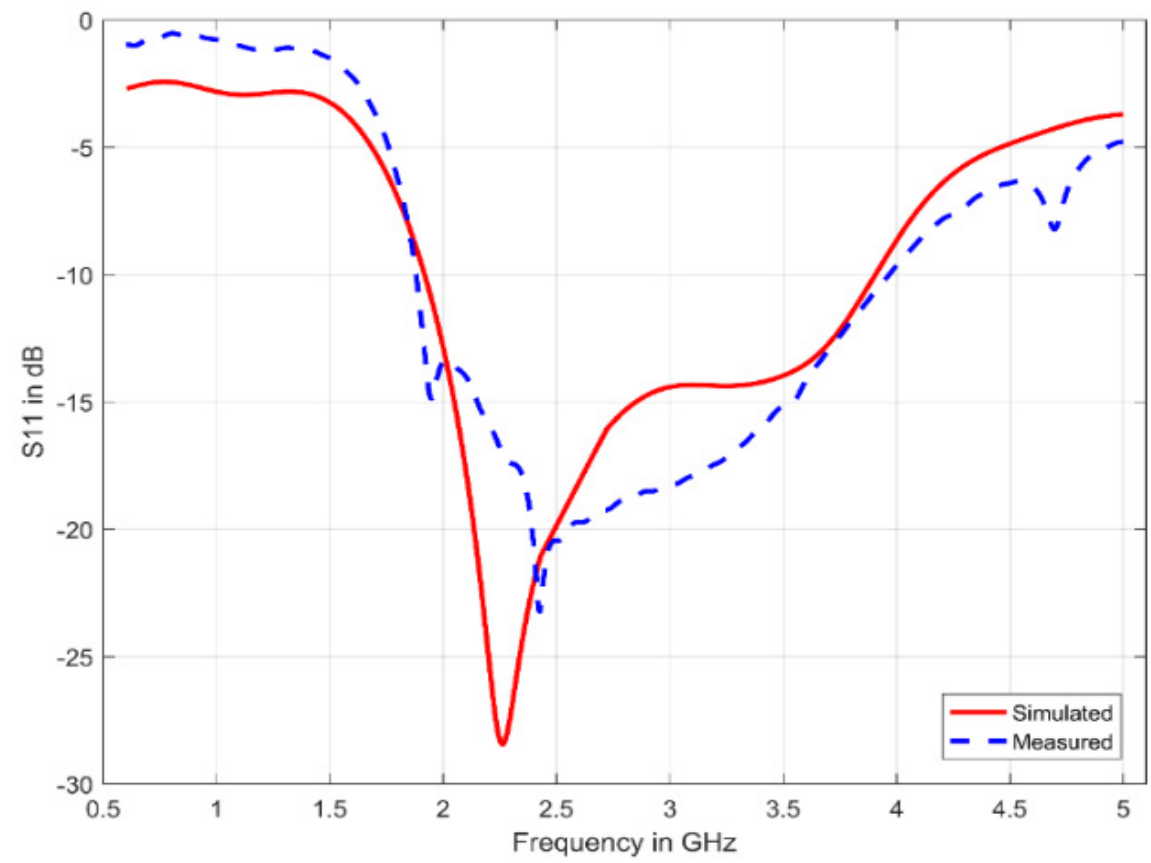

Figure 19. Measured and simulated S parameter for metamaterial integrated antenna.

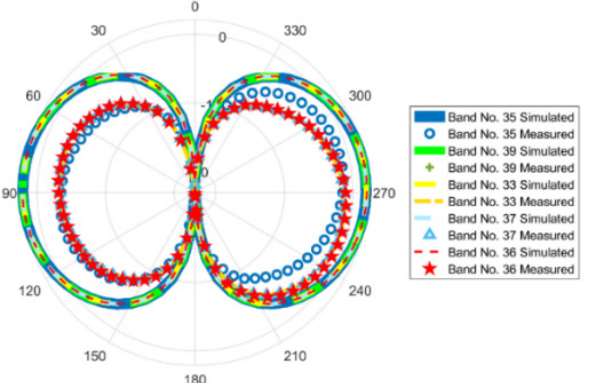

(a)

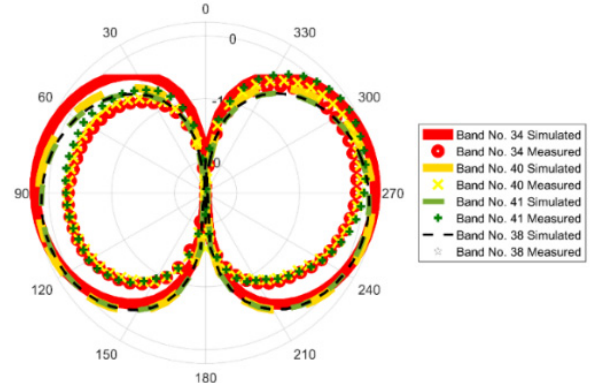

(b)

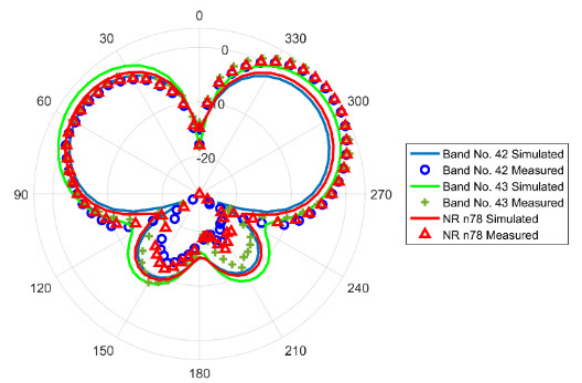

(c)

Figure 20. Metamaterial integrated antenna radiation pattern in the azimuth plane. (a) Low frequency bands. (b) Middle frequency bands. (c) High frequency bands.

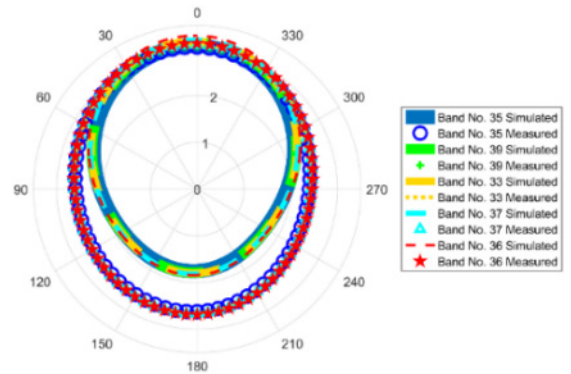

(a)

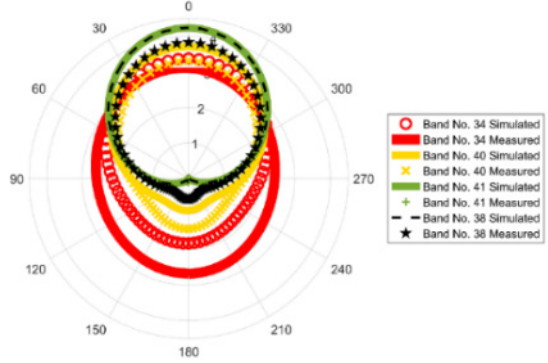

(b)

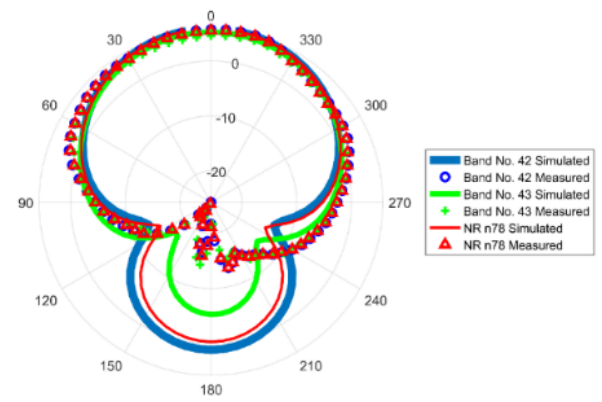

(c)

Figure 21. Metamaterial integrated antenna radiation pattern in the polar plane. (a) Low frequency bands. (b) Middle frequency bands. (c) High frequency bands.

Despite showing good antenna performance for mobile communication, the design needs to be incorporated with consideration of the radiation impacts on the human body [36]. The harmful effects of radiation can be investigated with the SAR evalua- 
tion of antenna design on the human body. SAR is the means of measuring absorbed radiations by the human body [37] and is expressed as:

$$
S A R=\frac{\sigma|E|^{2}}{\rho}
$$

where $E$ is the induced electric field, $\sigma$ is the conductivity of tissue and $\rho$ is the tissue density. There are various factors affecting the $S A R$ value, such as the tissue properties, geometry and spacing from the antenna. The $S A R$ simulation was examined using the CST SAM (Specific Anthropomorphic Mannequin) head phantom, because the antenna is designed for mobile applications and the head is the most exposed part in mobile radiation. The SAM consists of a plastic shell filled with tissue simulating liquid, and was defined for standardized certification purposes based on the 90th percentile of the head size of the male population [38]. The designed antenna is placed near to the left ear at a distance of $d$; the simulation setup for SAR analysis is illustrated in Figure 22.

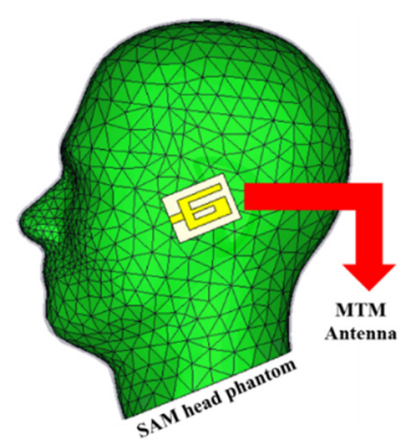

Figure 22. Illustration of SAR simulation setup.

According to the FCC guidelines, the maximum $S A R$ is restricted to $2 \mathrm{~W} / \mathrm{kg}$ averaged over $10 \mathrm{~g}$ of human tissue and $1.6 \mathrm{~W} / \mathrm{kg}$ averaged over $1 \mathrm{~g}$ of human tissue. The averaging method used in this analysis is per the IEEE C95.3 standard. The SAR is analyzed at $100 \mathrm{~mW}$ of input power for $1 \mathrm{~g}$ of tissue at a distance of $1 \mathrm{~mm}$ from the human head.

It was observed from the SAR analysis that the peak SAR value for the antenna without the metamaterial is less than $0.6751 \mathrm{~W} / \mathrm{kg}$ for all the bands. On the other hand, the metamaterial integration results in dwindling the SAR values by a significant amount with the lowest SAR of $0.0732 \mathrm{~W} / \mathrm{kg}$. The maximum SAR value observed for the antenna without the metamaterial was for band B25U, which was reduced by $57.47 \%$ with the integration of the metamaterial. The use of the metamaterial in the antenna design results in less radiation in the upper half for the polar plane. Thus, there is less radiation towards the head phantom, especially at high frequency LTE and NR n78 bands. The SAR dwindling percentage for all the bands is represented in the pie diagram of Figure 23. The major portion of SAR reduction is shown for the $7785 \mathrm{G}$ and LTE high frequency bands, with an average reduction of $84.2 \%$ in comparison to the operation without the metamaterial. The middle and low frequency LTE bands are reduced by an average of $21.2 \%$ and $53.6 \%$, respectively. In addition, the SAR observed for the IoT bands are reduced by an average of $50.1 \%$ in comparison to the operation without the metamaterial. The peak SAR values observed for the antenna design with and without the metamaterial are summarized in Table 5. Hence, very small amounts of SAR are observed for all the bands, which are considerably below the maximum allowed range of $1.6 \mathrm{~W} / \mathrm{kg}$. Hence, the integrated antenna design was demonstrated to be an excellent design for SAR reduction. 


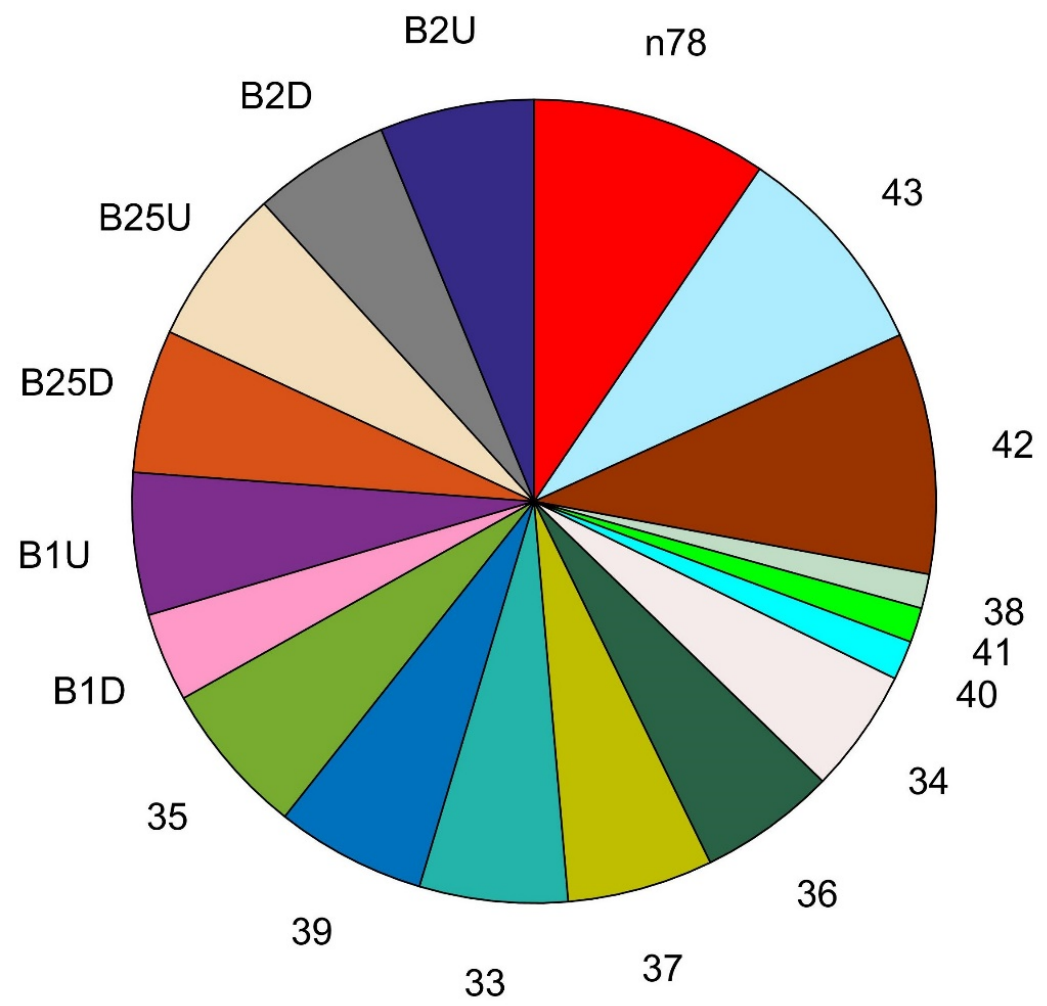

Figure 23. SAR minimization for different frequency bands.

Table 5. Peak SAR of antenna design.

\begin{tabular}{|c|c|c|c|c|}
\hline \multirow{2}{*}{ Band No. } & \multirow{2}{*}{ Band Name } & \multicolumn{2}{|c|}{ SAR (W/kg) } & \multirow{2}{*}{$\begin{array}{c}\text { SAR Minimization } \\
(\%)\end{array}$} \\
\hline & & Without Metamaterial & With Metamaterial & \\
\hline $\mathrm{B} 2 \mathrm{U}$ & \multirow{6}{*}{ IoT } & 0.6637 & 0.2907 & 56.20 \\
\hline B2D & & 0.6294 & 0.3152 & 49.92 \\
\hline B25U & & 0.6751 & 0.2871 & 57.47 \\
\hline B25D & & 0.6347 & 0.3028 & 52.29 \\
\hline B1U & & 0.6375 & 0.3071 & 51.83 \\
\hline B1D & & 0.5846 & 0.3953 & 32.38 \\
\hline 35 & \multirow{5}{*}{ Low frequency LTE } & 0.6637 & 0.2907 & 56.20 \\
\hline 39 & & 0.6565 & 0.2974 & 54.69 \\
\hline 33 & & 0.6525 & 0.3006 & 53.93 \\
\hline 37 & & 0.6483 & 0.3037 & 53.15 \\
\hline 36 & & 0.6294 & 0.3152 & 49.92 \\
\hline 34 & \multirow{4}{*}{ Middle frequency LTE } & 0.6005 & 0.3290 & 45.21 \\
\hline 40 & & 0.4853 & 0.4159 & 14.30 \\
\hline 41 & & 0.5225 & 0.4563 & 12.66 \\
\hline 38 & & 0.5243 & 0.4587 & 12.51 \\
\hline 42 & \multirow{2}{*}{ High frequency LTE } & 0.6053 & 0.0732 & 87.90 \\
\hline 43 & & 0.5723 & 0.1209 & 78.87 \\
\hline $\mathrm{n} 78$ & $5 \mathrm{G} \mathrm{NR}$ & 0.6027 & 0.0850 & 85.89 \\
\hline
\end{tabular}




\section{Conclusions}

This research provided a thorough study and assessment of a novel wideband folded dipole antenna. The structure of the antenna comprises a radiating folded arm to minimize the antenna's size. The controlling parameters are capable of tuning the performance of the folded arm and can be configured to synthesize the design for wide bandwidth requirements. The folded design is capable of covering the 5G NR n78, NR-IoT bands B1, B2, and B25, and eleven TDD LTE bands from 33 to 43 . The minimum scattering loss observed for the design was $-42 \mathrm{~dB}$ with $50.22 \Omega$ of input impedance. Furthermore, the folded dipole designed in this research is planar, compact $\left(35 \times 48 \times 1.62 \mathrm{~mm}^{3}\right)$ and simple in structure, thus enabling embedding in radio applications. In addition, the performance of the antenna design with metamaterial integration was also evaluated. A significant increase in gain was observed in antenna design for all operational frequency bands. It was observed that the metamaterial acts as a good absorber for radiation, especially at high frequency bands. The SAR investigation with and without metamaterial integration is also presented in this research. A tremendous decrease in SAR value was observed for all the operational bands, especially for the $7885 \mathrm{G}$ and LTE high frequency bands. The SAR value observed for all the bands was considerably below the acceptable peak value of $1.6 \mathrm{~W} / \mathrm{kg}$. Therefore, the antenna was proved to be a good candidate for mobile applications in terms of bandwidth, return loss, gain and SAR. The performance characteristics were verified by fabricating and testing a prototype. An excellent agreement was achieved between the simulated and measured results. The designed antenna can be used to address the issue of band congestion on a single chip for $4 \mathrm{G} / 5 \mathrm{G} / \mathrm{IoT}$ applications.

Author Contributions: Conceptualization, H.S., A.G. and N.M.; methodology, H.S., A.G., N.M., Y.K., M.W. and A.W.; software, H.S., A.G. and N.M.; validation, H.S., A.G., N.M., Y.K., M.W. and A.W.; investigation, H.S., A.G. and N.M.; writing-original draft preparation, H.S., A.G. and N.M.; writing-review and editing, Y.K., M.W. and A.W.; visualization, H.S., A.G., N.M., Y.K., M.W. and A.W.; supervision, M.W. and A.W.; project administration, A.W. and M.W.; funding acquisition, M.W. All authors have read and agreed to the published version of the manuscript.

Funding: This research received no external funding.

Institutional Review Board Statement: Not applicable.

Informed Consent Statement: Not applicable.

Acknowledgments: The authors acknowledge contribution to this project from the Rector of the Silesian University of Technology under a proquality grant no. 09/020/RGJ21/0007. Amtul Waheed would like to thank the Deanship of Scientific Research, Prince Sattam bin Abdul Aziz University, for supporting this work.

Conflicts of Interest: The authors declare no conflict of interest.

\section{References}

1. Patzold, M. It's Time to Go Big with 5G. IEEE Veh. Technol. Mag. 2018, 13, 4-10. [CrossRef]

2. Cao, J.; Yu, P.; Ma, M.; Gao, W. Fast authentication and data transfer scheme for massive NB-IoT Devices in 3GPP 5G Network. IEEE Internet Things J. 2019, 6, 1561-1575. [CrossRef]

3. Sesia, S.; Toufik, I.; Baker, M. LTE-The UMTS Long Term Evolution: From Theory to Practice; Wiley Publication: Hoboken, NJ, USA, 2009; ISBN 9780470742891.

4. Kelly, I.Y.; Perlow, H.W. Coexistence: The Theory and the Practice. IEEE Wirel. Commun. 2017, 24, 96-101. [CrossRef]

5. Selinis, I.; Katsaros, K.; Allayioti, M.; Vahid, S.; Tafazolli, R. The Race to 5G Era; LTE and Wi-Fi. IEEE Access 2018, 6, 56598-56636. [CrossRef]

6. Althuwayb, A.A. Enhanced radiation gain and efficiency of a metamaterial-inspired wideband microstrip antenna using substrate integrated waveguide technology for sub-6 GHz wireless communication systems. Microw. Opt. Technol. Lett. 2021, 63, 1892-1898. [CrossRef]

7. Hoglund, A.; Van, D.P.; Tirronen, T.; Liberg, O.; Sui, Y.; Yavuz, E.A. 3GPP Release 15 Early Data Transmission. IEEE Commun. Stand. Mag. 2018, 2, 90-96. [CrossRef] 
8. Lopez, N.; Lee, C.; Gummalla, A.; Achour, M. Compact Metamaterial Antenna Array for Long Term Evolution (LTE) Handset Application. In Proceedings of the International Workshop on Antenna Technology, IEEE, Santa Monica, CA, USA, 2-4 March 2009; pp. 1-4.

9. Lee, J.; Hong, Y.; Bae, S.; Abo, G.S.; Seong, W.; Kim, G. Miniature Long-Term Evolution (LTE) MIMO Ferrite Antenna. IEEE Antennas Wirel. Propag. Lett. 2011, 10, 603-606.

10. Ren, Y.J. Ceramic based small LTE MIMO handset antenna. IEEE Trans. Antennas Propag. 2013, 61, 934-938. [CrossRef]

11. Dioum, I.; Diallo, A.; Farssi, S.M.; Luxey, C. A novel compact dual-band LTE antenna-system for MIMO operation. IEEE Trans. Antennas Propag. 2014, 62, 2291-2296. [CrossRef]

12. Mun, B.; Jung, C.; Park, M.; Lee, B. A Compact Frequency Reconfigurable Multiband LTE MIMO Antenna for Laptop Applications. IEEE Antennas Wirel. Propag. Lett. 2014, 13, 1389-1392. [CrossRef]

13. Wong, K.; Liao, Z. Passive Reconfigurable Triple-Wideband Antenna for LTE Tablet Computer. IEEE Trans. Antennas Propag. 2015, 63, 901-908. [CrossRef]

14. Wong, K.; Chen, Y. Small-Size Hybrid Loop/Open-Slot Antenna for the LTE Smartphone. IEEE Trans. Antennas Propag. 2015, 63, 5837-5841. [CrossRef]

15. Chaturvedi, D. Asymmetric Coplanar Waveguide-Fed CRLH-TL based Antenn for WLAN/LTE Applications. In Proceedings of the International Conference on Circuit, Power and Computing Technologies, IEEE, Nagercoil, India, 19-20 March 2015; pp. 1-4.

16. Zhai, H. An LTE Base-Station Magnetoelectric Dipole Antenna with Anti-Interference Characteristics and Its MIMO System Application. IEEE Antennas Wirel. Propag. Lett. 2015, 14, 906-909. [CrossRef]

17. Chen, H.; Zhao, A. LTE Antenna Design for Mobile Phone With Metal Frame. IEEE Antennas Wirel. Propag. Lett. 2016, 15, 1462-1465. [CrossRef]

18. Mohammadi, M.; Kashani, F.H.; Ghalibafan, J. Backfire-to-endfire scanning capability of a balanced metamaterial structure based on slotted ferrite-filled waveguide. Waves Random Complex Media 2019, 1-15. [CrossRef]

19. Afzal, M.U.; Esselle, K.P.; Lalbakhsh, A. A Metasurface to Focus Antenna Beam at Offset Angle. In Proceedings of the 2018 2nd URSI Atlantic Radio Science Meeting (AT-RASC), Gran Canaria, Spain, 28 May-1 June 2018; pp. 1-4. [CrossRef]

20. Lalbakhsh, A.; Afzal, M.U.; Esselle, K.P. Multiobjective particle swarm optimization to design a time-delay equalizer metasurface for an electromagnetic band-gap resonator antenna. IEEE Antennas Wirel. Propag. Lett. 2017, 16, 912-915. [CrossRef]

21. Althuwayb, A.A. On-Chip Antenna Design Using the Concepts of Metamaterial and SIW Principles Applicable to Terahertz Integrated Circuits Operating over 0.6-0.622 THz. Int. J. Antennas Propag. 2020, 1-9. [CrossRef]

22. Lalbakhsh, A.; Afzal, M.U.; Hayat, T.; Esselle, K.P.; Mandal, K. All-metal wideband metasurface for near-field transformation of medium-to-high gain electromagnetic sources. Sci. Rep. 2021, 11, 9421. [CrossRef] [PubMed]

23. Mohammadi Shirkolaei, M.; Ghalibafan, J. Unbalanced CRLH behavior of ferrite-loaded waveguide operated below cutoff frequency. Waves Random Complex Media 2020, 1-16. [CrossRef]

24. Lai, A.; Caloz, C.; Itoh, T. Composite right/left-handed transmission line metamaterials. IEEE Microw. Mag. 2004, 5, 34-50. [CrossRef]

25. Alibakhshikenari, M.; Virdee, B.S.; Azpilicueta, L.; Naser-Moghadasi, M.; Akinsolu, M.O.; See, C.H.; Liu, B.; Abd-Alhameed, R.A.; Falcone, F.; Huynen, I.; et al. A Comprehensive Survey of "Metamaterial Transmission-Line Based Antennas: Design, Challenges, and Applications". IEEE Access 2020, 8, 144778-144808. [CrossRef]

26. Singh, H.; Sohi, B.S.; Gupta, A. Designing and analysis of cross-shaped CRLH metamaterial for wide band negative index characteristics. Mater. Res. Express 2019, 6, 75801. [CrossRef]

27. Singh, H.; Sohi, B.S.; Gupta, A. Thickness invariant parameter retrieval techniques for permittivity and permeability measurement. J. Microw. Power Electromagn. Energy 2018, 52, 215-239. [CrossRef]

28. Celik, A.R.; Kurt, M.B.; Kurt, M.B. Development of an ultra-wideband, stable and high-directive monopole disc antenna for radar-based microwave imaging of breast cancer breast cancer. J. Microw. Power Electromagn. Energy 2018, 52, 75-93. [CrossRef]

29. Ray, K.P.; Ranga, Y. Ultrawideband printed elliptical monopole antennas. IEEE Trans. Antennas Propag. 2007, 55, 1189-1192. [CrossRef]

30. Yang, Y.; Chu, Q.; Mao, C. Multiband MIMO Antenna for GSM, DCS and LTE Indoor Applications. IEEE Antennas Wirel. Propag. Lett. 2016, 15, 1573-1576. [CrossRef]

31. Zhao, L.; Chen, Z.M.; Wang, J. A Wideband Dual-Polarized Omnidirectional Antenna for 5G/WLAN. IEEE Access 2019, 7, 14266-14272. [CrossRef]

32. Zhao, A.; Ren, Z. Size Reduction of Self-Isolated MIMO Antenna System for 5G Mobile Phone Applications. IEEE Antennas Wirel. Propag. Lett. 2019, 18, 152-156. [CrossRef]

33. Jin, G.; Deng, C.; Xu, Y.; Yang, J.; Liao, S. Differential Frequency-Reconfigurable Antenna Based on Dipoles for Sub-6 GHz 5G and WLAN Applications. IEEE Antennas Wirel. Propag. Lett. 2020, 19, 472-476. [CrossRef]

34. Jin, G.P.; Deng, C.H.; Yang, J.; Xu, Y.C.; Liao, S.W. A New Differentially-Fed Frequency Reconfigurable Antenna for WLAN and Sub-6 GHz 5G Applications. IEEE Access 2019, 7, 56539-56546. [CrossRef]

35. Ciydem, M.; Miran, E.A. Dual-Polarization Wideband Sub-6 GHz Suspended Patch Antenna for 5G Base Station. IEEE Antennas Wirel. Propag. Lett. 2020, 19, 1142-1146. [CrossRef] 
36. Alibakhshikenari, M.; Babaeian, F.; Virdee, B.S.; Aissa, S.; Azpilicueta, L.; See, C.H.; Althuwayb, A.A.; Huynen, I.; Abd-Alhameed, R.A.; Falcone, F.; et al. A Comprehensive Survey on "Various Decoupling Mechanisms with Focus on Metamaterial and Metasurface Principles Applicable to SAR and MIMO Antenna Systems". IEEE Access 2020, 8, 192965-193004. [CrossRef]

37. Ahmed, G.; Islam, S.U.; Shahid, M.; Akhunzada, A.; Jabbar, S.; Khan, M.K.; Riaz, M.; Han, K. Rigorous Analysis and Evaluation of Specific Absorption Rate (SAR) for Mobile Multimedia Healthcare. IEEE Access 2018, 6, 29602-29610. [CrossRef]

38. Bang, J.; Choi, J. A SAR Reduced MM-Wave Beam-Steerable Array Antenna with Dual-Mode Operation for Fully Metal-Covered 5G Cellular Handsets. IEEE Antennas Wirel. Propag. Lett. 2018, 17, 1118-1122. [CrossRef] 